\title{
Refractory Digestive System Neuroendocrine Carcinoma
}

National Cancer Institute

\section{Source}

National Cancer Institute. Refractory Digestive System Neuroendocrine Carcinoma. NCI

Thesaurus. Code C155937.

A neuroendocrine carcinoma that arises from any part of the digestive system and does not respond to treatment. 